\title{
Aortobronchial fistula after correction of congenital cardiovascular abnormalities
}

\author{
S.C.A.M. Hiep-van Casteren*, C.J.J. Westermann*, R.P.H.M. Hamerlijnck**, \\ P.H.J.G.M. Cornelissen**, T.Th.C. Overtoom ${ }^{+}$
}

Aortobronchial fistula after correction of congenital cardiovascular abnormalities. S.C.A.M. Hiep-van Casteren, C.J.J. Westermann, R.P.H.M. Hamerlijnck, P.H.J.G.M. Cornelissen, T.Th.C. Overtoom. CERS Journals Ltd 1995.

ABSTRACT: Aortobronchial fistula (ABF) is a rare but highly lethal condition. Four patients with ABF, 10-25 years after surgical repair of a congenital cardiovascular abnormality are reported.

All patients presented with haemoptysis. Computed tomographic (CT) scan and aortography were inconclusive in two, diagnostic in one and not performed in another. Three patients underwent operation: all survived and are free of symptoms with a follow-up of 2-8 yrs. The fourth patient died before operation due to massive haemorrhage into the lung. In all patients, the fistula was secondary to aortic interposition of patch grafts.

Eur Respir J., 1995; 8, 1796-1798.
Depts of *Pulmonology, **Thoracic surgery and +Radiology St. Antonius Hospital, Nieuwegein, The Netherlands.

Correspondence: C.J.J. Westermann

Dept of Pulmonology

St. Antonius Hospital

Koekoekslaan 1

3435 CM Nieuwegein

The Netherlands

Keywords: Aortobronchial fistula

false aneurysm aorta

haemoptysis

Received: December 141994

Accepted after revision May 131995
Haemoptysis secondary to aortobronchial fistulization (ABF) is rare and fatal if not treated surgically. The first patient operated upon was reported by JONES [1] in 1947. Since 1934, 79 cases of aortobronchial fistula have been described, but only 20 of these were related to previous surgery for a congenital anomaly (patent ductus arteriosus (PDA) in three patients, coarctation repair in 15 patients, PDA with coarctation in one, and congenital aortic arch hypoplasia in another) [1-9].

Four patients with $\mathrm{ABF}$ as a late complication after correction of congenital vascular anomalies are described; three of whom were operated upon successfully.

\section{Case reports}

Patient A, a 29 year old male, was admitted to hospital twice in 3 months with massive haemoptysis. He had had a coarctation repair at 15 yrs of age, but specific details of the operation were not available. Bronchoscopy revealed some fresh blood in the left lung. Chest radiograph, computed tomography (CT) scan and aortography disclosed a modest re-coarctation and a small bulge on the left dorsal side of the proximal descending aorta (fig. 1). No extravasation of contrast was noted, following selective injection in the bulge. Embolization of two pathological bronchial arteries was carried out. However, massive haemoptysis $(1,500 \mathrm{~mL})$ recurred.

Under the suspicion of $\mathrm{ABF}$, left thoracotomy was performed and a small aortobronchial fistula was found just distal to the anastomosis, corresponding with the bulge seen on aortography. A piece of vascular prosthetic graft was found and removed; the aortic defect was closed by direct suture and covered by thymic fat. Haemoptysis did not recur during the 2 years of follow-up.

Patient B, a 40 year old male, was admitted to another hospital because of recurrent left-sided haemoptysis (10-150 mL fresh blood daily for 5 months). He had been operated upon three times in the past for tetralogy of Fallot (Pott's shunt at 3 yrs of age; total correction with closure of the Pott's at 21 yrs of age; closure of a residual ventricular septum defect at 23 yrs of age). Detailed descriptions of the operations were lacking. At

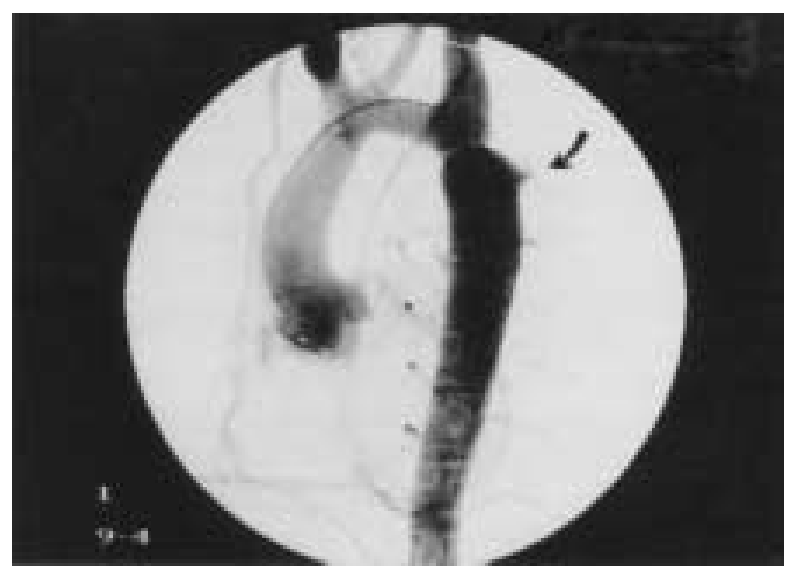

Fig. 1. - Aortography of patient A shows slight narrowing at the siteof the anastomosis and a small bulge (arrow), initally not interpreted as an aortobronchial fistula $(\mathrm{ABF})$. 
bronchoscopy, blood was seen in the left upper lobe. Two small saccular aneurysms of the aorta were seen on aortography and CT-scanning. The left bronchial artery was embolized as it showed abnormalities. However, haemoptysis persisted and the patient was referred to our hospital for further investigation and therapy. Unfortunately, he suffocated due to massive haemoptysis from the left bronchial tree.

Autopsy revealed an atherosclerotic aorta with an aneurysm around a prosthetic patch, and with several fistulas extending into the adjacent pulmonary parenchyma.

Patient C, a 45 year old male, complained of severe back pain with recurring haemoptysis a year prior to admission. At that time no specific diagnosis was made. He presented with haemoptysis of increasing frequency (150 mL daily). At 20 yrs of age, he had undergone operative correction of a coarctation. The operative report could not be retrieved. Bronchoscopy localized the source of bleeding in the left upper lobe. A CT-scan and aortography disclosed an aneurysm of the descending aorta and a dot of contrast suggesting the presence of an ABF.

Left thoracotomy confirmed a communication between the lung parenchyma and a $6 \mathrm{~cm}$ wide false aneurysm adjacent to a piece of Teflon felt. A segmentectomy was performed and all Teflon felt was removed. A new aortic prosthesis was inserted and covered with a pericardial flap and a thymic fat pad. Four years later, he has had no further haemoptysis.

Patient D, a 22 year old male, was admitted in shock with acute chest pain and massive haemoptysis. At 12 yrs of age, he had been operated upon for coarctation of the aorta. The chest radiograph showed complete shadowing of the left hemithorax, with a mediastinal shift to the right. The serum haemoglobin was $4.4 \mathrm{mM} \cdot \mathrm{L}^{-1}$ (71 $\left.\mathrm{gL}^{-1}\right)$ and pleural aspiration yielded blood.

At emergency thoracotomy, a ruptured false aneurysm was found at the suture line of a prosthetic patch. Resection and aortic repair was performed with a new vascular prosthesis, which was covered with surrounding tissue. Haemoptysis has not recurred in the subsequent 8 years.

\section{Discussion}

Aortobronchial fistula $(\mathrm{ABF})$ is a rare but highly lethal condition. The majority $(90 \%)$ of cases involve an aneurysm of the thoracic aorta $[2,10,13]$. Tuberculosis and luetic aortitis used to be the principal causes of these aneurysms with fistulization $[4,10]$. Recently, however, postsurgical and atherosclerotic aneurysms have become the main causes [2, 4]. Atherosclerotic aneurysms occur in older patients, whilst postsurgical aneurysms can be found in patients of any age and especially in the young who have had surgical correction of congenital anomalies, as was the case in the four patients presented. After the repair of coarctation, the late development of false aneurysm is related to the surgical technique used. The incidence after end-to-end anastomosis is only $1 \%$. However, when a Dacron vascular graft is used this increases to $7 \%$, whilst the use of patch plasty results in an incidence of $20 \%$ to even $24 \%$ [8, 11, 12]. The presence of foreign material (prosthetic patches, Teflon felt, vascular prosthetic grafts or even suture material) can evoke an inflammatory response, with subsequent adherence of the foreign material to the lung parenchyma and the formation of ABF [13]. In the four cases described, there appears to be a direct relationship between ABF and the presence of foreign material. It is of prime importance to have detailed information on the type of repair performed, as is shown in patient B. Due to lack of proper information, adequate therapeutic measurements were postponed resulting in a fatal delay.

The presenting symptom of ABF is haemoptysis, variable in duration and in volume. Massive haemoptysis, defined as the expectoration of $600 \mathrm{~mL}$ of blood in $24 \mathrm{~h}$, occurs in $79 \%$ and is often the terminal event [10]. Three of the four patients had massive haemoptysis. Chest pain is another frequent symptom; it is found in $45 \%$ of the patients so far reported, and two of our patients presented with pain.

Bronchoscopy is useful to locate the site of the bleeding (on the left-side in $92 \%$ of patients with $\mathrm{ABF}$ ) and to exclude endobronchial abnormalities [13]. Bronchial artery angiography can be misleading. In two patients, pathological bronchial arteries were thought to be the cause of bleeding and these were therefore embolized. However, only when haemoptysis recurred after embolization, was ABF suspected and was diagnosed by operation in patient A. CT-scanning and aortography should always be performed because they will show an aneurysm if present. However, they will seldom show the fistula, since it is often filled with clot. ABF was suggested by aortography in patient $\mathrm{C}$, but missed in patient $\mathrm{B}$. In patient A, only a small bulge was found in the descending aorta; thoracotomy showed it to be an aortobronchial fistula and no aneurysm was found. We have no experience with magnetic resonance imaging (MRI), which shows the thoracic aorta and its relationship to adjacent structures [2,6]. MRI has been recommended as the screening method of choice [6].

An aortobronchial fistula should always be treated surgically. During operation, it is important to remove all old prosthetic material, since it may be the source of persistent inflammation. Sometimes a pulmonary resection is necessary because of the inflammatory response. Depending on the size of the new defect, a prosthetic graft may be required, although sometimes the fistula can be closed by direct suture. To prevent direct contact between the vascular reconstruction and the pulmonary tissue, the new graft and suture lines should be covered by the remains of the aneurysm wall, if present, or by surrounding viable tissue, such as intercostal muscle, pleural or pericardial flaps, thymic fat or even by an omental pedicle [3]

In conclusion, $\mathrm{ABF}$ must be considered in any patient with major or minor haemoptysis and a history of thoracic aortic surgery. Urgent examination is required because fatal haemoptysis may occur at any moment. Early diagnosis followed by surgical correction results in a survival rate of more then $80 \%$ [10]. Long-term survival and quality of life after correction are good. 


\section{References}

1. Jones JC. Complications of the surgery of patent ductus arteriosus. J Thorac Surg 1947; 16: 305-313.

2. Caes F, Taeymans Y, van Nooten G. Aortobronchial fistula: a late complication of coarctation repair by patch aortoplasty. Thorac Cardiovasc Surg 1993; 41: 80-82.

3. Graeber GM, Farrel BG Jr, Neville JF Jr, Parker FB. Successful diagnosis and management of fisulas between the aorta and the tracheobronchial tree. Ann Thorac Surg 1980; 29: 555-561.

4. Gross-Fengels W, Friedmann G, Pippert H, Krüger J, Aortobronchiale Fisteln als Spätkomplikationen nach operativer Korrektur von Aortenisthmusstenosen. Dtch Med Wschr 1991; 116: 1274-1278.

5. Hartung HW, de Vivie ER, Hasse F, et al. Rupture of a thoracic aortic aneurysm after prosthetic bypass from the ascending aorta to the descending aorta in a case of congenital aortic arch hypoplasia. Thorac Cardiovasc Surg 1985; 33: 48-50.

6. Holdright DR, Kilner PJ, Somerville J. Haemoptysis from false aneurysm: near fatal complication of repair of coarctation of the aorta using a Dacron patch. Int $J$ of Cardiol 1991; 32: 406-408.
7. Miller JP, Cammarata SK. Massive hemoptysis 17 years after repair of aortic coarctation. Chest 1994; 105: $1249-1250$.

8. Aebert H, Laas J, Bednarski P, Koch U, Prokop M, Borst HG. High incidence of aneurysm formation following patch plasty repair of coarctation. Eur J Cardiothorac Surg 1993; 7: 200-205.

9. Gehling U, Knopp M, Saggau W, Schultz V. Aortopulmonary fistula formation after operation of aortic isthmus stenosis as a rare cause of recurrent hemoptysis. Pneumologie 1992; 46: 587-590.

10. Demeter SL, Cardasco EM. Aortobronchial fistula: keys to successful management. Angiology 1980; 31: 431-435.

11. Koller M, Rothlin M, Senning A. Coarctation of the aorta: review of 362 operated patients. Long-term follow-up and assessement of prognostic variables. Eur Heart Journal 1987; 8: 670-679.

12. Bromberg BI, Beekman RH, Rocchini AP, et al. Aortic aneurysm after patch aortoplasty repair of coarctation: a prospective analysis of prevalence, screening tests and risks. J Am Coll Cardiol 1989; 14: 734.

13. Macintosh EL, Parrot JCW, Unruh HW. Fistula between the aorta and tracheobronchial tree. Ann Thorac Surg 1991; 51: 515-519. 